style of decoration with glazed briclss was borrowed by the Persians, and we see it in the splendid decoration from Persepolis now in the Louvre at Paris.

It is to be hoped that Dr. Koldewey has still more important discoveries in store.

H. R. HALL.

\section{THE NEGLECT OF GROUP-THEORY}

THE volume of "Proceedings of the London Mathematical Society," second series, vol. vii., contains twenty-six papers by such well-known mathematicians as Bateman, Bromwich, Burnside, Dickson, Dixon (A. C., and A. L.), Hardy, Harrison, Hobson, Lamb, Littlewood, Macdonald, Pidduck, Sommerville, and Young. While these are mainly of too technical a character to admit of discussion in this notice, attention should be directed to some remarks in Prof. Burnside's address on the "Theory of Groups of Finite Order," as affording an object-lesson on the important question of "England's neglect of mathematics.' Prof. Burnside states :-

"It is undoubtedly the fact that the theory of groups of finite order has failed, so far, to arouse the interest of any but a very small number of English mathematicians; and this want of interest in England, compared with the amount of attention devoted to the subject both on the Continent and in America, appears to me very remarkable." "So far as I have been able to learn, no course of lectures has ever been delivered either at Oxford or Cambridge on the theory of groups of finite order." "In fact, so far as the teaching of the subject in England is concerned, one may say that it does not exist."

It appears that during the twenty-one years of the now, alas! defunct "Part II." of the Mathematical Tripos, questions on finite groups have only appeared four times, and that it is doubtful whether four candidates have seriously studied the subject.

On the other side we have the following statement:

"In Paris M. Jordan gives a course on the theory of groups of finite order at the Collège de France at regular intervals to an average class of six students, while the Galois theory of equations is lectured on at the Sorbonne and the École normal, as well as at one or two of the provincial universities.

"In most German universities, the regular course of lectures on algebra, attended by large classes of students, contains an exposition of the more elementary parts of the theory of groups of permutations. In addition to this there are, in all the larger universities, special courses devoted to groups of finite order and to discontinuous groups, which attract a considerable number of students. For instance, such special courses last year were attended at Göttingen by thirty students, and at Freiburg by twelve.

"In the United States all the leading universities offer regular courses in the theory of groups of finite order, with the exception of Harvard, where a course is given on the Galois theory of equations. In some cases the course is a yearly cne, and in the others it is biennial. These courses attract from two or three up to ten or twelve students, who in general have already taken the B.A. degree.'

Prof. Burnside offers some explanations for this neglect, but probably the reason is a very simple one. If any English mathematician specialises in the theory of groups (and at least one instance is known to the reviewer) no university will offer him adequate remuneration for a course of lectures on the subject; on the other hand, the mathematical departments of English institutions of university rank are deplorably understaffed in comparison with those in foreign countries, and their teachers are far too overburdened with elementary work to be able to start courses or a subject like "groups," in addition to meeting the necessary requirements of their examination syllabuses. Prof. Burnside suggests that the cause may partly be NO. 2 I 49 , VOL. 85$]$ a lack of demand for instruction in the subject on the part of senior university students. But is it not the fact that such students are induced to give up advanced mathematical study and to take to experimental science in order to qualify for "research studentships?" If they persist in specialising in higher mathematics of any kind, they not infrequently do so at the risk of injuring their future prospects of obtaining appointments.

\section{NOTES.}

Political services and commercial prosperity appear to be the claims to distinction of most of the people whose names are to be found in the list of New Year Honours. The list includes the names of few men of eminence in the intellectual world-whether of science, art, or literature. One Fellow of the Roval Society-Dr. David Ferrier-has been knighted; and among the twenty-four other new knights are Dr. H. B. Donkin, Mr. G. Laurence Gomme, and Dr. G. Newman. Even in these cases, however, the honour appears to have been conferred for public services rather than in recognition of scientific work. The list has been received with the usual chorus of congratulation by the daily papers, but it can in no way be regarded as truly representative of the men who are rendering the best services to the nation.

The Oceanographical Institute provided by the Prince of Monaco at Paris will be inaugurated on Monday, January 23 .

IT is announced that an association for the promotion of science, to be called the "Kaiser Wilhelm Gesellschaft," will shortly be formed in Germany. The first meeting of the association is to be held within the next week or two under the presidency of Prof. Emil Fischer, and the German Emperor proposes to be present.

The Paris Academy of Sciences, at a meeting on December 29, I9ro, discussed the question of the election of women as members of the Institute of France. We learn from the Times that the academy eventually came to the conclusion that each section of the institute has complete independence with regard to the election of members, and that each academy has the right to decide the question of the election of women to its membership. The subject is being discussed at a general meeting of the academies as we go to press.

WE regret to see the announcement of the death of one of the best known supporters of amateur astronomy in Germany, Dr. M. Wilhelm Meyer, who died recently at Meran, at the comparatively early age of fifty-eight. Dr. Meyer's astronomical carcer began at Geneva, of which observatory he was for a short time director. $\mathrm{He}$ signalised his connection with that observatory by an attempt to determine the density of the material near the nucleus of a comet by observing the displacement of stars over which the comet passed; but he is better known from his relations with the Urania Gesellschaft in Berlin and his efforts to encourage astronomical studies in "those who frequented the observatory. $\mathrm{He}$ was successful in attracting those who were capable of using the equipment provided wisely and well. Among his pupils or followers may be mentioned Herr Witt, who discovered the planet Eros in the Urania Observatory. Many of his popular works have had a wide circulation, among which may be mentioned "Das Weltgebaude," a work addressed to those who were capable of following the detailed explanation of the more difficult problems in astronomy, and the 